\title{
A Framework for the Adoption of Blockchain-Based e-Procurement Systems in the Public Sector A Case Study of Nigeria
}

\author{
Temofe Isaac Akaba ${ }^{1}$, Alex Norta ${ }^{1(\bowtie)}(\mathbb{D})$, Chibuzor Udokwu ${ }^{1}$, \\ and Dirk Draheim ${ }^{2}$ (D) \\ 1 Blockchain Technology Group, Tallinn University of Technology, \\ Akadeemia tee 15a, 12618 Tallinn, Estonia \\ \{temofe.akaba, chibuzor.udokwu\}@taltech.ee, alex.norta.phd@ieee.org \\ 2 Information Systems Group, Tallinn University of Technology, \\ Akadeemia tee 15a, 12618 Tallinn, Estonia \\ dirk.draheim@taltech.ee
}

\begin{abstract}
Public procurement constitutes a core government function for providing goods and services to citizens. The overall success of a digitized public-procurement function yields progress and economic growth for the nation. In this research, we analyze the potential of blockchainbased systems to enhance effectiveness, ease, and transparency in public procurement in the case of Nigeria and identify the current challenges facing public procurement, i.e., lack of trust and transparency among critical stakeholders in the procurement process, systems that only weakly support transaction recording and documentation, complex process structures, corruption in institutions involved in the procurement process. To address these issues, a blockchain-based framework is developed to enable interoperability of information-systems involved in the procurement process, increase citizen participation in eliciting project requirements and to enable a more transparent project monitoring and auditing. We apply the framework to a case study with respect to identifying onchain activities that enable system interoperability, e-participation and project auditability.
\end{abstract}

Keywords: Blockchain $\cdot$ Procurement $\cdot$ Smart contract $\cdot$ Interoperability $\cdot$ Project-monitoring

\section{Introduction}

Public procurement is a core function of government activities that catalyzes economic growth and development, if conducted efficiently and transparently. Despite these benefits of e-procurement, developing nations, including Nigeria, still struggle with issues ranging from a lack of trust and transparency among 
the important participants in the process, systems that only weakly support transaction recording and documentation, complex process structures and massive corruption in institutions within the process. The exchange of corruption money between companies and government officials to be awarded government contracts is estimated to comprise $15 \%$ of the contract value.

With respect to these challenges, an innovative approach for tracking all aspects of public procurement for trust, transparency, and ease within the system is essential. Thus, blockchain technology [25] creates a decentralized platform for validating transactions, data and information that are independent of any third party control in a verifiable, secured transparent and permanent set-up. Therefore, blockchain technology [1] has the potential to be adopted to offer solutions for public e-procurement.

In this paper, we propose a blockchain-based e-procurement framework that takes into consideration key success factors in public procurement using Nigeria as a case [3]. We commence with a thorough analysis of the procurement system in Nigeria by conducting semi-structured interviews with twelve high-level stakeholders and experts. Based on the findings of this analysis, the framework elaboration yields a set of concrete recommendations as a concept study, i.e., we provide a first evaluation of the framework's feasibility with application to the Nigerian case.

The remainder of the paper is structured as follows. In Sect.2, we discuss related work and in Sect.3, we explain details of the used research method. In Sect. 4 , the case selection, subject description and results of the interviews are presented. Next, in Sect. 5, we elaborate the framework and Sect. 6 provides a mapping of the current procurement process to a blockchain-based solution. The paper finishes in Sect. 7 with a conclusion, limitations, open issues and future work.

\section{Related Work}

Public procurement is a vital part of government processes that present value for citizens [11]. The normal flow of a public procurement process includes: crafting an annual budget with the different estimated needs of government agencies, making a plan for the procurement of the items listed in the project, issuing a call for tender for interested contractors, conducting financial- and technical evaluations of participating firms and finally, the award and implementation of projects. The objective of these activities is the delivery of high-quality and timely services to citizens through public programs and -application projects.

Blockchain innovations and application are an emerging area of technology research $[19,20]$. Research on this technology is very diverse and previous work includes the application of blockchain in regular currencies and centralizedbanking systems to curb corruption in the finance industry [16]. In [12], the authors suggest apply blockchain technology for handling and securing patient records, recording an audit trail and securing data due to its decentralized features, compare also with [4]. As another example, blockchain research related 
to supply-chain management focuses on reducing counterfeiting and accuracy in document-validation processes [24]. Within the context of e-Government, research in blockchain technology is explored in various fields, i.e., in the area of identity management [21] and document authentication [23], compare also with [1] versus conventional approaches such as [7], or in specialized fields such as land registration [14].

Blockchain technology application in procurement processes is on a slow but steady rise since technology infusion in this process is still vision- and experiment-oriented rather than a solution-based scientific endeavour [17]. According to [10], blockchain technology has a high potential to significantly improve procurement systems, in particular, with respect to data integration across business functions. Thus, the infusion of blockchain technology causes a positive shift in the way organizations carry out procurement, thereby creating more possibilities for growth and expansion on a global scale.

\section{$3 \quad$ Research Methodology}

We perform semi-structured interviews with twelve stakeholders and experts in public procurement, private-sector procurement, blockchain technology and advocacy for transparency and technology adoption in the Nigerian public-sector procurement. The respondents are made up of fourteen experts from relevant procurement-related organizations including the National Identity Management Commission (NIMC), private firms, civil societies and the National Assembly.

The idea for this diverse pool of respondents is to acquire a holistic compilation of ideas from a diverse set of knowledgeable stakeholders. The interview data we analyze with thematic analysis, supported by RQDA ( $\mathrm{R}$ package for Qualitative Data Analysis $)^{1}$. In the data analysis, we follow six well-defined steps proposed by [15].

\section{The Case of the Nigerian Procurement System}

Information about Nigeria and the procurement context, we first present in Sect. 4.1. Next, Sect. 4.2 gives the interview results.

\subsection{Case- and Subject Description}

The Nigerian government has encountered severe problems in public procurement $[2,8]$. According to [22], these problems have existed despite of - and even due to - the enactment of the Public Procurement Act in 2007 to ensure transparency, competitiveness, value for money and professionalism in the publicsector procurement system. The Procurement-Act guidelines demand from stakeholders the following strict rules and provides guidelines for the establishment

$\overline{{ }^{1} \text { http://rqda.r-forge.r-project.org/. }}$ 
of an approving body, i.e., the National Council on Public Procurement, as well as a regulatory body, i.e., the Bureau of Public Procurement.

Still, the objectives of the act are in far reach due to the poor implementation of the relevant directives that can ultimately be traced to the harsh economic, social- and political environment in the country. According to [9], public procurement in Nigeria remains the most common means through which public funds have been misappropriated and stolen for personal and individual gains. Although the adoption of e-procurement is a goal, most of the functions are still operated manually and as such prone to corruption and fraud.

\subsection{Interview Results}

The interviews are structured in different sections. The first section is concerned with gaining background knowledge of the respondents to assess the validity of their responses. The other sections focus on gathering interview findings we categorize into the themes existing procurement system, stakeholder involvement and role, influencing factors for adopting blockchain-based procurement, criteria for assessing effectiveness. The project $\log ^{2}$ shows the detailed interview transcript for this research.

Existing Procurement System. The respondents express that, although the regulators aim to introduce e-procurement, the existing manual procedures are still used extensively. Furthermore, the respondents state unnecessary emphasis on rule compliance is detrimental to fair and transparent procurement processes.

Respondents mention the lack of clear structure of project planning and execution within the ministries, departments and agencies (MDAs). This structure absence renders it impossible for the Bureau of Public Procurement to install improvement plans. Approximately $50 \%$ of our respondents mention that corruption currently exists in all phases of the procurement process from project planning via bidding to the project implementation stage.

Stakeholders Involvement. Investigating stakeholder involvement indicates the impact on their roles and duties of adopting automating systems. To acquire a holistic understanding, we gather responses from private-sector respondents who mention that planning is a very crucial success factor of the procurement function as they perform a thorough analysis of the intended goods, services, or project. The study further explores the specific steps taken by contractors and suppliers who provide goods and services for clients who communicate via emails, or phone calls. Most respondents indicate they do not move beyond a re-order level to have stock available in the case of an emergency. In cases where the procuring entity is a large organization such as a government ministry, respondents usually place orders directly from the international manufacturers

\footnotetext{
${ }^{2}$ Project Log https://www.researchgate.net/publication/338102329_Interview_ Transcript.
} 
as opposed to using intermediaries. This reduces the delivery time and enables specific demand of the procuring entity to be met.

The role and involvement of the Bureau of Procurement is also explored during the research. A senior official of the Bureau mentions that, apart from acting as a regulator, the bureau also advises the government about the procurement and disposal of public goods and services. Finally, the role of civil-society organizations is considered, in particular, to monitor and track public-sector procurement, funding and financing. Two respondents who work with different civil-society organizations explain despite challenges, the government aims to ensure a more transparent and open system. With the slow progress of change, the respondents wish the government adopts technologies and systems for ease, efficiency, and transparency to meet the global standard for public procurement.

Influencing Factors for Adopting Blockchain-Based Procurement. In this section, we analyze the factors that hinder the effective implementation of a blockchain-based solution as well as how these issues can be addressed. The areas of a hindrance include a poor infrastructure set up, lack of political will of the government to implement necessary technology policies needed, lack of funding for a full implementation, resistance to change by public officials, and poor knowledge of blockchain technology by stakeholders involved in the process.

A number of $33 \%$ of the respondents specifically mention the epileptic power situation in Nigeria as the main challenge to fully implement blockchain technology that can not effectively run. Additionally, three respondents mention the need for political will both from the executive- and legislative arms in ensuring total compliance with the requirements needed for a functioning blockchain use. Poor technology knowledge is another challenge to adopt a blockchain system. Similarly, another respondent mentions that although these stakeholders would stall blockchains and use traditional methods of moving files to manipulate figures and engage in fraud and corruption that an advanced and digitized system restricts.

To correct these identified issues, respondents unanimously point out the need for training all procurement staff and other stakeholders to gain a better understanding of what the proposed blockchain technology entails and how it functions. One respondent particularly stresses the government ensuring maintaining and sustaining blockchain technologies.

Criteria for Assessing Effectiveness. It is also crucial to understand appropriate effectiveness-assessment criteria for novel blockchain-technology based systems. In summary, the following points are mentioned by the respondents: ease, transparency, affordability, communication- and feedback mechanisms, knowledge of blockchain systems and interoperability with existing databases. All respondents express the opinion that any successful new blockchain system must be easy to use and needs to support public servants in their daily routines. As the current processes are usually stressful and time consuming, a novel blockchain system is expected to solve these problems to gain full acceptance. 
With respect to transparency, $67 \%$ of the respondents agree that a successful blockchain system must adequately take into account transparency and openness with respect to all aspects of the procurement process. One respondent suggests that the possibility of linking the procurement system with other national databases such as of the Corporate Affairs Commission, creates significantly more monitorable openness about the ownership of firms that win bids to execute contracts. According to the respondents, these criteria must be present and evaluated continuously to ensure that novel blockchain technology for e-procurement is active and functional.

\section{A Framework for Blockchain-Based Procurement}

Based on the findings in Sect.4.2, we propose a novel framework that aims at enabling public organizations to implement and increase the adoption of blockchain-based procurement systems. In crafting this framework, a blockchain system is considered mainly because it possesses a shared, immutable and decentralized ledger for recording transactions and tracking assets in a network. Assets in this sense are anything of value and may be tangible, e.g., land and buildings, vehicles and machineries, or intangible such as intellectual properties, patents, copyrights, etc. These assets can be recorded, tracked and traded within a blockchain network.

The concepts of immutability, decentralization and trust renders blockchains a very transparent and efficient system for recording transactions as all relevant stakeholders maintain a level of equality and access in tracking processes. Blockchain technology provides security, ensures anonymity and enhances data integrity of transactions without any third party involved [26]. In addition, there is a time-stamp for data that is stored in a block linked to the preceding block for validation to create a chain of blocks. These features render blockchains a veritable choice for a secured and trusted system in business applications. The framework is presented as a set of recommendations in Table 1.

Table 1. Recommendation for blockchain implementation and -adoption in procurement processes.

\begin{tabular}{l|l|l}
\hline Problem category & Findings & Recommendation \\
\hline $\begin{array}{l}\text { Existing procurement } \\
\text { system }\end{array}$ & $\begin{array}{l}\text { Corruption resulting from manual } \\
\text { processes, because existing systems } \\
\text { involved in public procurement are not } \\
\text { interoperable }\end{array}$ & $\begin{array}{l}\text { Blockchain integration } \\
\text { into existing systems }\end{array}$ \\
\hline $\begin{array}{l}\text { Stakeholder involvement } \\
\text { and roles }\end{array}$ & $\begin{array}{l}\text { Lack of a clear channel of } \\
\text { communication and an effective } \\
\text { system that can track the process }\end{array}$ & $\begin{array}{l}\text { Blockchain-supported } \\
\text { user engagement and } \\
\text { collaboration }\end{array}$ \\
\hline $\begin{array}{l}\text { Criteria for assessing } \\
\text { effectiveness }\end{array}$ & $\begin{array}{l}\text { Lack of transparency and openness of } \\
\text { procurement processes, affordability, } \\
\text { feedback mechanisms, knowledge of } \\
\text { the system }\end{array}$ & $\begin{array}{l}\text { Blockchain-based } \\
\text { project auditing and } \\
\text { monitoring }\end{array}$ \\
\hline
\end{tabular}


Three recommendations are presented and each recommendation is associated to a problem category. The first recommendation addresses the issue of corruption in existing processes due to the absence of interoperability in the systems that support the current procurement process. The proposed framework recommends using blockchain-enabled smart contracts [18] to facilitate interoperability of current systems. This results in increased automated processes and, thereby, reduces corruption cases in the procurement processes.

The second proposal involves engaging stakeholders in the procurement process and establishing clear communication channels. With roles that are clearly defined and assigned to all stakeholders, the citizens participate in eliciting service requirements before a particular project proposal is submitted. Thus, ensuring that, all stakeholders involved in the procurement processes behave according to legislation.

The final recommendation addresses the issue of assessing the effectiveness of the procurement system, processes and completed projects. The framework proposes a blockchain-based solution that is capable of tracking and monitoring the projects that are executed under the procurement. This increases the transparency and openness of the procurement processes and also provides an avenue for feedback mechanisms on executed projects.

Permissioned blockchain systems possess restrictions that limit the actions that can be taken by participants within a network to yield a strong option for future public sector application [5]. In addition, a private blockchain ensures that only parties involved in the e-procurement process can participate in the blockchain network, thereby ensuring the privacy of information, or data shared in a public procurement process. The study [13] shows how privacy can be ensured in public networks and thereby demonstrates the possibility of implementing this public procurement process in a public blockchain.

\section{Mapping the Existing Procurement Process to a Blockchain}

We apply the proposed blockchain-implementation framework presented in Sect. 5 for mapping on-chain activities for the current public procurement process. First, we present the $A S$ - $I S$ version of the procurement processes using BPMN (Business Process Model and Notation) [6] as a diagram notation and then show the activities that are executed on-chain based on our proposed framework. Section 6.1 shows the AS-IS version of the procurement process and Sect. 6.2 also comprises the on-chain activities.

\subsection{AS-IS Procurement Process}

The process begins with a procurement plan crafted by the MDA to ascertain current infrastructural and project gaps that need to be filled and provided for. Next, a budget is specified and sent to the National Assembly for appropriation. Projects that are not needed are cancelled and after the budget is passed by 
the National Assembly and signed into law by the executive, the projects are executed. Here, the budget is sent to the Parastatals Tender Board (PTB), or the Ministerial Tenders Board (MTB) for further checks and approval, in particular, on whether the price is within the approval thresholds. Once, the tender boards then approve the budget, a call for tender is placed in the news dailies for potential contractors. Otherwise, the budget is sent to the Bureau of Public Procurement. Once the latter receives the budget, they perform further reviews and approve if a budget is within their approval limits. Otherwise, the proposal is sent to the Federal Executive Council for further consideration and approval.

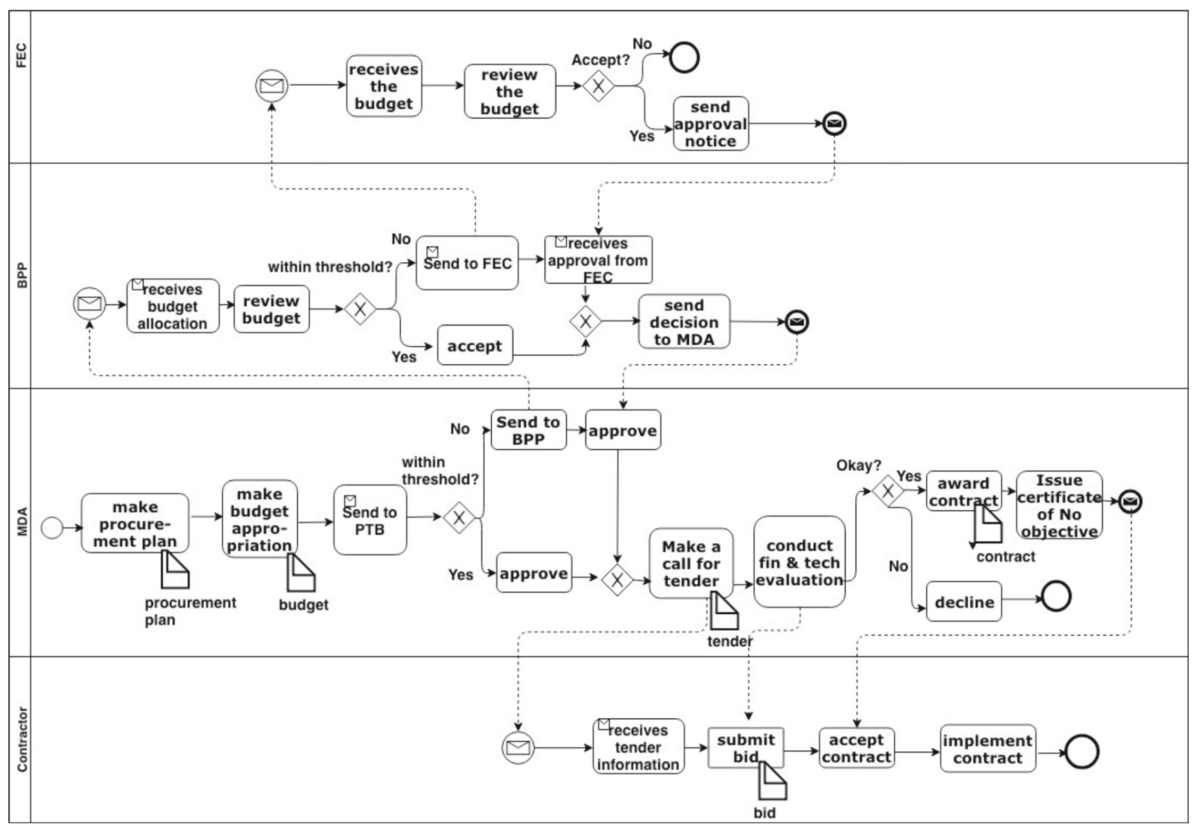

Fig. 1. Current AS-IS state of the public procurement process.

Once there is an approval for the project to be executed, a call for tender is issued on national dailies and contractors are expected to submit their bids. After the submission of bids, a technical- and financial evaluation is conducted, and the contract is awarded to the most qualified bidder with a certificate of no objection issued. Alternatively, the bid is declined if any irregularities are found during the technical- and financial evaluation stage. Once the process flow is completed, the project is implemented. 


\subsection{On-Chain Activities in the Procurement Process}

These on-chain activities show the procurement activities that can be executed on the blockchain to achieve the goals of the recommendations in the proposed framework. First, we identify tasks in the existing process as shown in Fig. 1 that enable interoperability of all the silo systems of the organizations involved in the procurement process when they are implemented on a blockchain system. Thus, assets associated with these tasks are stored on the blockchain and accessed via the information systems of the collaborating parties. We further identify additional tasks for on-chain implementation to enable stakeholder involvement in outlining service requirements of submitted projects. Finally, we identify procurement tasks that need to be monitored on a blockchain by the citizens to increase transparency and auditability of the procurement process.

Table 2. Enabling on-chain tasks.

\begin{tabular}{l|l|l}
\hline Associated task & Assets stored on-chain & Stakeholders \\
\hline On-chain tasks enabling system interoperability & \\
\hline Specify procurement plan & Procurement plan & MDA/BPP \\
\hline Specify budget appropriation & Budget & BPP/FEC \\
\hline Submit call to tender & Tender & All Stakeholders \\
\hline Award contract & Contract & MDA/Contractor \\
\hline Submit bid & Bid & MDA/Contractor \\
\hline Additional on-chain task enabling stakeholders engagement \\
\hline Vote on project needs & Prioritized project requirement & MDA/Citizens \\
\hline Additional on-chain task enabling project auditability and monitoring \\
\hline \multicolumn{4}{l}{ Vote on completed project } & project assessment result & MDA/Citizens \\
\hline
\end{tabular}

Enabling Stakeholders Systems Interoperability: Table 2 shows the executed tasks on blockchain and resulting assets that are also stored on-chain. This results in the interoperability of information systems of collaborating parties in the procurement process. Access to the assets are only granted to stakeholders that are associated to the task. Therefore, only a single version of an asset exists that cannot be illegally modified, or tampered by any malicious, or corrupt stakeholder in the procurement process.

Enabling Stakeholders Engagement: The current procurement process depicted in Fig. 1 does not show how stakeholders such as citizens are actively engaged in the procurement process. Based on our proposed framework, the citizens engage in the process by eliciting requirements included in a project. The call for tender shows the service requirements of the project and bids are submitted by contractors based on the requirements contained in the tender. 
As depicted in Table 2, to engage citizens in the procurement process, an additional on-chain activity must be implemented such that citizens are able to vote on project requirements that are prioritized in the call for tender. The result of a vote is stored as an asset on the blockchain and the stakeholders involved are represented by the MDA and concerned citizens.

Enabling Project Auditability and Monitoring: The current procurement process does not show any activity resulting in transparent monitoring and an evaluation of completed projects. This is another main source of corruption in the existing process, since projects are not properly monitored and payments are issued to contractors that already failed to execute according to the requirements listed in the project tenders. Therefore, an additional on-chain activity is required to render the evaluation of completed projects more democratic and transparent. Using blockchain-enabled smart-contracts, citizens can track projects based on the requirements on the tender and vote 'success' when the executed projects successfully satisfy the requirements in a tender. Otherwise, the project is considered as failure. As per Table 2, further actions can be taken by the MDAs based on the citizens' project assessment result.

\section{Conclusion}

This research explores the existing public procurement processes to understand the overall structure, complexities and challenges that need to be faced in proposing a workable blockchain-based framework. Twelve high-level stakeholders and experts we interview for this purpose. The main challenges that we identify are corruption and a lack of transparency within the procurement process. An indepth analysis reveals the underlying structural- and communication issues. On this basis, we recommend an implementation framework that aims at interoperability of all the silo systems of the involved organizations. Thus, all assets associated with crucial tasks are stored on a blockchain and accessed via the collaborating parties - creating more openness, transparency and trust.

As a further outcome, we discover that the current procurement process does not adequately support citizen engagement. For this issue, we propose an additional on-chain activity so that citizens can vote on project requirements that are prioritized during the call for a tender stage. Finally, we seek to find answers to the important aspects of project monitoring, evaluation and auditability. Our respondents mention that most of the budgeted projects are only poorly executed, or not completed at all. With respect to this, we propose an additional on-chain activity that renders the evaluation of the completed projects more democratic and transparent - by giving citizens access to track projects based on the tender requirements and allowing them to give feedback about the success, or failure based on these requirements.

A limitation of this research is the generalization power given the focus on one e-procurement case of Nigeria. Secondly, the cost of implication for the proposed blockchain-based system is also not fully considered, especially additional 
costs associated to blockchain activities, i.e., commonly referred to as transaction fee. As future research, we consider investigating the factors and challenges that deepen, or affect citizen involvement in the usage of blockchain technology. Secondly, the aspect of security and privacy for blockchain technology is not fully considered in this research.

\section{References}

1. Abodei, E., Norta, A., Azogu, I., Udokwu, C., Draheim, D.: Blockchain technology for enabling transparent and traceable government collaboration in public project processes of developing economies. In: Pappas, I.O., et al. (eds.) I3E 2019. LNCS, vol. 11701, pp. 464-475. Springer, Cham (2019). https://doi.org/10.1007/978-3030-29374-1_38

2. Adewole, A.: Governance reform and the challenge of implementing public procurement law regime across Nigerian state and local governments. Int. J. Public Adm. Manage. Res. (IJPAMR) 2(4), 25-32 (2014)

3. Akaba, T.I.: A framework for the adoption of a blockchain-based e-procurement system: a case study of Nigeria. Master's thesis, Tallinn University of Technology, Tallinn, Estonia (2019)

4. Azogu, I., Norta, A., Draheim, A.: A framework for the adoption of blockchain technology in healthcare information management systems a case study of Nigeria. In: Proceedings of ICEGOV 2019: The 12th International Conference on Theory and Practice of Electronic Governance. ACM (2019)

5. Baliga, A.: Understanding blockchain consensus models. Persistent 2017(4), 1-14 (2017)

6. Chinosi, M., Trombetta, A.: BPMN: an introduction to the standard. Comput. Stan. Interfaces 34(1), 124-134 (2012)

7. Draheim, D., Koosapoeg, K., Lauk, M., Pappel, I., Pappel, I., Tepandi, J.: The design of the Estonian governmental document exchange classification framework. In: Kö, A., Francesconi, E. (eds.) EGOVIS 2016. LNCS, vol. 9831, pp. 33-47. Springer, Cham (2016). https://doi.org/10.1007/978-3-319-44159-7_3

8. Ezeh, M.E.: Public procurement reform strategies: achieving effective and sustainable outcomes. In: CIPS Pan Africa Conference. National Theatre, Accra, Ghana, pp. 21-22 (2013)

9. Fayomi, I.O.: Public procurement and due process policy in Nigeria: trust, prospects and challenges. Peak J. Soc. Sci. Humanit. 1(4), 39-45 (2013)

10. Geissbauer, R., Weissbarth, R., Wetzstein, J.: Procurement 4.0: are you ready for the digital revolution? Strategy - part of the PwC network, 4 May 2016

11. Khan, N.: Public Procurement Fundamentals: Lessons from and for the Field (Includes A Simple Step-By-Step Generic Procurement Manual). Emerald Publishing Limited, Bingley (2018)

12. Kuo, T.T., Kim, H.E., Ohno-Machado, L.: Blockchain distributed ledger technologies for biomedical and health care applications. J. Am. Med. Inform. Assoc. 24(6), 1211-1220 (2017)

13. Ladleif, J., Weske, M., Weber, I.: Modeling and enforcing blockchain-based choreographies. In: Hildebrandt, T., van Dongen, B.F., Röglinger, M., Mendling, J. (eds.) BPM 2019. LNCS, vol. 11675, pp. 69-85. Springer, Cham (2019). https:// doi.org/10.1007/978-3-030-26619-6_7 
14. Lazuashvili, N., Norta, A., Draheim, D.: Integration of blockchain technology into a land registration system for immutable traceability: a casestudy of Georgia. In: Di Ciccio, C., et al. (eds.) BPM 2019. LNBIP, vol. 361, pp. 219-233. Springer, Cham (2019). https://doi.org/10.1007/978-3-030-30429-4_15

15. Maguire, M., Delahunt B.: Doing a thematic analysis: a practical, step-by-step guide for learning and teaching scholars. AISHE-J: All Ire. J. Teach. Learn. Higher Educ. 9(3) (2017)

16. Nicholson, J.: The library as a facilitator: how bitcoin and block chain technology can aid developing nations. Ser. Libr. 73(3-4), 357-364 (2017)

17. Nicoletti, B.: A business model for insurtech initiatives. The Future of FinTech. PSFST, pp. 211-249. Springer, Cham (2017). https://doi.org/10.1007/978-3-31951415-4_8

18. Norta, A.: Self-aware smart contracts with legal relevance. In: 2018 International Joint Conference on Neural Networks (IJCNN), pp. 1-8. IEEE, July 2018

19. Norta, A., Draheim, D.: In: First Workshop on Blockchains for Inter-organizational Collaboration. Proceedings of the CAiSE 2018 International Workshops, volume 316 of Lecture Notes in Business Information Processing, pp. 99-102. Springer (2018)

20. Norta, A., Leiding, B., Draheim, D., Karastoyanova, D., Pufahl, L., Schöning, S.: In: BIOC \& FAiSE 2019 - Joint Workshop on Blockchains for Inter-organizational Collaboration and Flexible Advanced Information Systems. Proceedings of the CAiSE 2019 International Workshops. LNBIP, Springer (2019)

21. Norta, A., Matulevičius, R., Leiding, B.: Safeguarding a formalized blockchainenabled identity-authentication protocol by applying security risk-oriented patterns. Comput. Secur. 86, 253-269 (2019)

22. Olatunji, S.O., Olawumi, T.O., Odeyinka, H.A.: Nigeria's public procurement lawpuissant issues and projected amendments. Public Policy Adm. Res. 6(6), 73-85 (2016)

23. Ølnes, S., Ubacht, J., Janssen, M.: Blockchain in government: benefits and implications of distributed ledger technology for information sharing. Gov. Inf. Q. 34(3), 355-364 (2017)

24. Toyoda, K., Mathiopoulos, P.T., Sasase, I., Ohtsuki, T.: A novel blockchain-based product ownership management system (POMS) for anti-counterfeits in the post supply chain. IEEE Access 5, 17465-17477 (2017)

25. Udokwu, C., Kormiltsyn, A., Thangalimodzi, K., Norta, A.: The state of the art for blockchain-enabled smart-contract applications in the organization. In: 2018 Ivannikov Ispras Open Conference (ISPRAS), pp. 137-144. IEEE (2018)

26. Yli-Huumo, J., Ko, D., Choi, S., Park, S., Smolander, K.: Where is current research on blockchain technology? - a systematic review. PLoS ONE 11(10), e0163477 (2016) 